\title{
AS MARCAS DO AGRONEGÓCIO SOBRE O TERRITÓRIO DAS ÁGUAS DA BACIA DO PRATA
}

\author{
Vera Lucia Fortes Zeni ${ }^{1}$ \\ Luiz Fernando Scheibe ${ }^{2}$ \\ Elton Zeni ${ }^{3}$ \\ Marcilei Andrea Pezenatto Vignatti ${ }^{4}$
}

Resumo: Brasil, Paraguai, Uruguai, Bolívia e Argentina compartilham os rios Paraguai, Uruguai e Paraná e as águas subterrâneas do Sistema Aquífero Integrado Guarani/Serra Geral, que compõem a bacia do Prata. Os usos dessas águas envolvem diferentes escalas de poder especialmente pelo agronegócio, o qual estabeleceu fronteiras agrárias configurando novos territórios. Tomando os conceitos de território e escala como ferramentas intelectuais metodológicas, este artigo faz uso de pesquisa bibliográfica e documental, explicitando os resultados territoriais das disputas ao longo dos processos de apropriação da água como recurso, evidenciando que a lógica mercantilista produz alterações na paisagem local, forjando conflitos na organização social do território.

Palavras-chave: Bacia do Prata. Território. Agronegócio.

\section{THE STAINS OF THE AGRIBUSINESS OVER THE TERRITORY OF THE WATERS IN THE BASIN PLATA}

Abstract: Argentina, Bolivia, Brazil, Paraguay and Uruguay, share the Paraná, Paraguay and Uruguay rivers and the groundwater of the Guarani/Serra Geral Integrated Aquifer System (SAIG/SG), that compose the Basin Plata. The uses of those waters include different power levels especially by the agribusiness, which established agricultural frontiers configuring new territories. Taking the concepts of territory and scale as intellectual and methodological tools, this paper uses bibliographical and documental research, explaining the results of the disputes through the appropriation processes of the water as resource, highlighting that the mercantilist logic makes changes in the local landscape, building conflicts in the social organization of the territory.

Key words: Plata Basin. Territory. Agribusiness.

\section{LAS MARCAS DEL AGRONEGOCIO EN EL TERRITORIO DE LAS AGUAS DE LA BACIA DEL PLATA}

Resumen: Brasil, Paraguay, Uruguay, Bolivia y Argentina comparten los ríos Paraguay, Uruguay y Paraná, y las aguas subterráneas del Sistema Acuífero Integrado Guaraní/Sierra Geral que componen la cuenca del Plata. El uso de estas aguas depende de diferentes niveles de poder especialmente por el agronegocio, que ha establecido fronteras agrarias ajustando nuevos territorios. Con la aplicación de los conceptos de territorio y escala como herramientas intelectuales metodológicas, este artículo utiliza pesquisa bibliográfica y documental, explicando los resultados territoriales de las disputas durante los procesos de apropiación del

\footnotetext{
1 Unidade Central De Educação Faem Faculdade, Chapecó-SC, Brasil, verazeni@yahoo.com.br https://orcid.org/0000-0001-6631-5345.

2 Universidade Federal de Santa Catarina, Departamento de Geociências, Florianópolis, Brasil, scheibe2@gmail.com,https://orcid.org/0000-0002-5275-9671.

${ }^{3}$ Unidade Central De Educação Faem Faculdade, Chapecó, Brasil, elton@uceff.edu.br, https://orcid.org/0000-0002-0967-0540

${ }^{4}$ Universidade Comunitária da Região de Chapecó, CCHJ, Chapecó, marcileiv@unochapeco.edu.br, https://orcid.org/0000-0003-2531-4201.
} 
agua como recurso, evidenciando que la lógica mercantilista produce cambios en el paisaje local, forjando conflictos en la organización social del territorio.

Palabras clave: Cuenca del Plata. Territorio. Agronegocio.

\section{Introdução}

A água é um bem natural comum entre os países que compõem o território da Bacia do Prata, possível causador de divergências geopolíticas, especialmente porque seu uso diverge, conforme o objetivo (comumente econômico) de cada país em relação ao recurso hídrico.

A hidrografia platina por meio de sua função, é fator definidor de muitas territorialidades nessa bacia internacional, onde as fronteiras foram sendo demarcadas através da mais valia da água, gerando conflitos diplomáticos ou forçando tratados, acordos e integrações. Esse fato está explícito historicamente quando as discórdias pelas delimitações espaciais fronteiriças eram pela função da água para navegação para a busca da prata em Potosí, para transporte de mercadorias, para produção agrícola nas missões jesuíticas. Neste caso, a água foi se tornando elemento importante não somente como definidora de fronteiras, mas componente primordial para o desenvolvimento dos países ribeirinhos e inserção no mercado internacional gerando territorialidades e novas formas de extração de renda, acumuladas a partir dos recursos hídricos. Espíndola (2009, p.144) denominou esse uso como "renda da água":

Os territórios de recursos hídricos são espaços globais de produção (assim como, espaços de poder) visto que a gestão dos recursos hídricos, também como a de qualquer outro recurso natural só assume plenamente seu significado enquanto parte de um esforço de realização de renda, não só em benefício da própria economia usuária, mas também como estímulo a um fluxo de transferência sempre crescente, entre setores, regiões ou países (ESPÍNDOLA, 2009, p. 144).

A sociedade moderna diversificou usos da água para geração de riqueza expressada nas relações de poder, causadas pelas demandas cada vez maiores. Espíndola (2009) explica que esse fato acontece devido à "multifuncionalidade" da água: para o autor, "Territórios de recursos hídricos podem funcionar tanto no abastecimento, quanto na produção de energia, no transporte e no turismo, bem como podem tomar a função de meio de produção na pesca e na aquicultura" (ESPÍNDOLA, 2009, p. 143). Essa produção pode ser observada nos dados apresentados no documento publicado pelo Conselho Intergovernamental da bacia do Prata_CIC: 


\begin{abstract}
Argentina tiene un porcentaje de $12,8 \%$ de tierra cultivable, lo cual representa 35 millones de hectáreas de su territorio nacional. Este es el mayor porcentaje en la Cuenca, seguido por Brasil, Paraguay y Uruguay, respectivamente. Las provincias argentinas que la integran producen el $90 \%$ de los cereales del país (soja, maíz y girasol), aceites de semillas y mantienen un $70 \%$ de su stock bovino, generando el $60 \%$ del PBI del país. También se cultiva algodón, tabaco, porotos, caña de azúcar, cítricos y arroz (CIC-ANÁLISIS DIAGNÓSTICO TRANSFRONTERIZO DE LA CUENCA DEL PLATA - ADT, 2016, p. 79).
\end{abstract}

A pesquisa analisa as territorialidades instauradas pelo agronegócio na bacia do Prata, usando os conceitos de território e escala como ferramentas intelectuais metodológicas. Essa investigação faz uso de pesquisa bibliográfica e documental, por meio de fontes procedentes de levantamentos em órgãos governamentais dos países abrangidos pela bacia e instituições independentes.

O artigo foi divido em seis sessões para apresentar as marcas do agronegócio sobre o território das águas da Bacia do Prata; a primeira aborda os dados do território da Bacia e os motivos das disputas geopolíticas pelos usos das águas.

A segunda, "O agronegócio redefinindo territórios", demonstra a dependência do uso intensivo da água pelos grupos agroindustriais e as alterações na paisagem local, forjando conflitos na organização social do território. A terceira, "Os negócios territoriais e seus vínculos" aborda as transformações territoriais numa economia cada vez mais financeirizada. A quarta sessão trata de "A lógica das grandes escalas de cultivos reflete nas escalas locais", expulsando do campo boa parte dos pequenos agricultores. Na sequência, a sessão "O agronegócio e sua infraestrutura: hidrovia Paraguai-Paraná" reforça a dupla importância econômica das águas, tanto como fonte de vida dos produtos, quanto de sua distribuição geográfica através da navegabilidade, assim necessitando de investimentos públicos, a serviço do agronegócio. Para finalizar, a sexta sessão avalia o conjunto dos "Impactos dos diferentes usos das águas platinas", produzidos pela lógica mercantilista que utiliza os recursos naturais, em suas múltiplas funções, gerando perturbações negativas e conflitos societários, no solo, na flora, na fauna e nas águas superficiais e águas subterrâneas.

\title{
Agronegócio e o território das águas
}

$\mathrm{Na}$ sociedade capitalista, os tempos e espaços globalizados e tecnológicos têm, direta ou indiretamente, influenciado em todos os aspectos da vida geopolítica, 
sociocultural, ambiental e econômica. As transformações técnicas, a relativização, o imediatismo, a agilidade, a mobilidade de fronteiras, as territorializações e, sobretudo, o progresso da ciência, têm pautado decisivamente as relações humanas e, consequentemente, a dinâmica do agronegócio no espaço dos países que ocupam o grande território da Bacia do Prata (ZENI, 2018).

A Bacia do Prata abrange quase todo o centro sul brasileiro $\left(1.415 .000 \mathrm{~km}^{2}\right)$, seguido pela Argentina com uma extensa região do seu centro norte $\left(920.000 \mathrm{~km}^{2}\right)$, todo o Paraguai $\left(410.000 \mathrm{~km}^{2}\right)$, o sudeste da Bolívia $\left(205.000 \mathrm{~km}^{2}\right)$ e grande parte do Uruguai $\left(150.000 \mathrm{~km}^{2}\right)$. É formado pelas bacias dos rios Paraguai, Paraná e Uruguai e pode ser subdividido em sete sub-bacias: Alto Paraguai, Baixo Paraguai, Alto Paraná e Baixo Paraná, Alto e Baixo Uruguai e Rio da Prata, no estuário (Figura 1).

\section{Figura 1: Bacia do Prata}

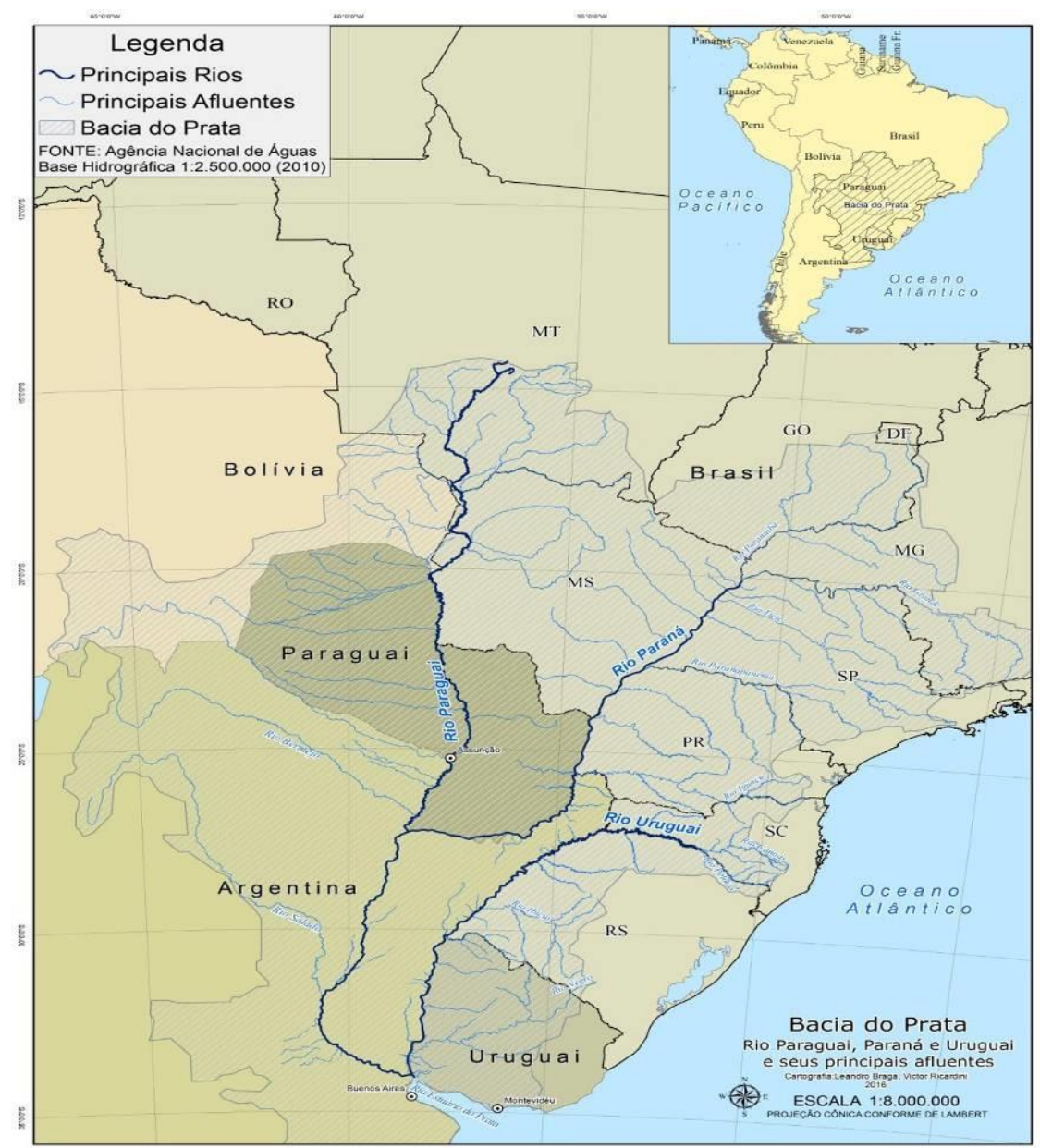

Fonte: Base cartográfica: CIC Plata - organizado pelos autores.

Conforme dados do CIC (2018), 70\% do PIB desses países é gerado nesta bacia, onde se localiza $50 \%$ da respectiva população, totalizando 110 milhões de 
habitantes. Abrange 57 cidades com mais de 100.000 habitantes, incluindo as capitais: Buenos Aires, Brasília, Assunção, Montevidéu e Sucre - capital administrativa da Bolívia.

$\mathrm{Na}$ perspectiva dos dados econômicos e populacionais, na contemporaneidade, esse território é ambiente propício para a formação de diferentes territorialidades, constituídas a partir dos múltiplos usos da água: navegação, energia, agricultura, pecuária, pesca, turismo, indústria, usos domésticos entre outros.

A questão central desse dinamismo é a intensificação da agricultura nos últimos 40 anos. A Bacia platina é hoje importante produtora de inúmeros itens agrícolas, entre eles soja, milho, trigo, arroz, carnes (bovinocultura, suinocultura, avicultura). Para produzi-los, o território vai sendo demarcado e degradado:

Práticas agrícolas em grande escala,para a intensificação da produção de soja desde o início dos anos 90, e o desenvolvimento de uma das maiores indústrias da criação de gado no mundo, resultaram na compactação do solo, redução da infiltração de água, aumento de escoamento superficial e problemas de sedimentação (CIC, 2016, p. 52).

O Brasil tem um dos maiores rebanhos de carne bovina do mundo, segundo a Farmnews 5 (em 8 de março de 2017), com 226 milhões de bovinos - 22,6\% do total de animais do planeta -, numeros que se traduzem em impactos, resultado de uma atividade agrícola comercial exportadora que se relaciona com as mudanças do uso

Quadro 01 - Agronegócio nos países platinos

\begin{tabular}{|c|c|}
\hline ARGENTINA & $\begin{array}{l}\text { - 12, } 8 \% \text { terra arável, representa } 35 \text { milhões de hectares de seu território nacional. } \\
\text { - São produzidos na bacia, } 90 \% \text { dos cereais (soja, milho e girassol), óleos de sementes e } 70 \% \text { do } \\
\text { gado, gerando } 60 \% \text { do PIB do país. } \\
\text { Outros cultivos: algodão, tabaco, feijão, cana-de-açúcar, frutas cítricas e arroz. }\end{array}$ \\
\hline BRASIL & $\begin{array}{l}\text { Bacia do Rio Uruguai = culturas de subsistência, gado, produção de soja, milho, e arroz; no Alto } \\
\text { Uruguai produção intensiva de suínos e aves, e crescente de leite e derivados. } \\
\text { Bacia do Rio Paraguai = soja e gado. } \\
\text { Bacia do Rio Paraná = 57\% da extensão ocupada com pastagens, criação de } 10 \% \text { do gado do país, } \\
\text { produção de laranjas, soja, cana de açúcar e café. }\end{array}$ \\
\hline PARAGUAI & $\begin{array}{l}\text { A agricultura ocupa a região leste, com predominância de soja e pastagens para pecuária. } \\
\text { A margem direita do rio Paraguai, na região Chaquenha, concentra a área agrícola que foi mantida } \\
\text { estável, embora nos últimos anos observou-se uma diminuição na área ocupada para esta } \\
\text { atividade, devido à grande expansão do gado no centro do Chaco e secas frequentes. }\end{array}$ \\
\hline URUGUAI & $\begin{array}{l}80 \% \text { do gado é criado na bacia platina, incrementando o setor lácteo. Além da horticultura e } \\
\text { cultivo de árvores frutíferas, milho, cevada, arroz e aveia. }\end{array}$ \\
\hline
\end{tabular}

Fonte: Elaborado pelos autores (2018), a partir do CIC (2016).

5 Farmnews é um canal de notícias diárias com análises exclusivas do mercado pecuário e agrícola. Disponível em: <http://www.farmnews.com.br/analises-mercado/produtores-de-carne-bovina/>.

Acesso em: 19 dez. 2018. 
As economias da Argentina, Brasil e Uruguai possuem marcante produção pecuária, na região do pampa. Argentina e Uruguai, além das explorações bovinas, produzem ovelha de boa qualidade exportadora. Porém, o cultivo de arroz com irrigação é um grande vilão do consumo das águas platinas.

As regiões hidrográficas com maiores demandas de água para os arrozais correspondem ao Sul do Brasil, norte do Uruguai e leste da Argentina, na sub-Bacia transfronteiriça do Rio Quaraí (14.657 km²), afluente do Rio Uruguai. Nessas regiões há um expressivo número de reservatórios para irrigação, forjando conflitos entre os usos para cultivo comercial e o abastecimento humano, especialmente nos períodos de seca, quando as cidades ficam com deficiência de água para consumo.

Menezes; Trentin (2014, p. 385), que interpretaram o cultivo do arroz de forma separada nas porções brasileira (que representa $46 \%$ da área) e uruguaia (54\% da área total da sub-bacia do Quaraí), demonstram com precisão que o uso principalmente associado à orizicultura é mais intenso na porção brasileira, da qual ocupa 19,9\%, contra 15,8\% da segunda. Assim, a demanda por água para suprir o cultivo na porção brasileira é maior, embora territorialmente seja menor que a porção uruguaia: apresenta um maior uso associado a lavouras.

Pela concentração da orizicultura, na época da irrigação a expressiva demanda chega a esgotar muitos dos cursos de água, mesmo nas condições hidrológicas normais. Perante esse fato, os conflitos pelo uso da água são inevitáveis e, na medida em que as áreas sob irrigação aumentam, cresce também o potencial de conflito (MENEZES; TRENTIN, 2014, p. 390).

Diante do exposto, existe a necessidade de gerenciar em formato bilateral o uso das águas transfronteiriças desta bacia, pois sem água torna-se inviável o plantio deste cereal; não resolve incluir as melhores e mais adequadas tecnologias, solos, sementes ou insumos, se não houver disponibilidade de água; por mais que no momento a Bacia do Prata tenha água suficiente para a produção deste alimento, seu uso não pode ser negligenciado. Esse cultivo precisa ser sustentável e ecologicamente correto, pois é na bacia hidrográfica que se revela a maioria das sequelas e impactos do mau uso das suas águas:

Eles se manifestam como: erosão dos solos, lixiviação de nutrientes, sedimentação de rios, lagos e reservatórios, degradação de matas ciliares e da cobertura vegetal, deposição de resíduos sólidos, dejetos e efluentes decorrentes de atividades humanas, cheias e inundações, endemias e epidemias de veiculação hídrica. Essa é uma das razões para que a bacia seja tomada como a unidade fisiográfica de planejamento (BRASIL, 2014, p. 26). 
Outro problema grave são as perdas de água: no Brasil, segundo o mesmo documento, com base no Plano Nacional de Recursos Hídricos, $69 \%$ da água consumida tem utilização na agricultura irrigada, com eficiência média de $64 \%$ : ou seja, $36 \%$ da água derivada para a irrigação no país constituem-se em perdas por condução e por distribuição nas infraestruturas hidráulicas, provocando um grande desperdício no uso da água na agricultura (BRASIL, 2014, p. 40).

\title{
O agronegócio redefinindo territórios
}

A agricultura é a principal atividade econômica na bacia platina, do ponto de vista da ocupação do território, conforme dados do CIC (2016, p. 18): "[...] cerca de $40 \%$ da cobertura original foi substituída por áreas de uso humano. Agricultura e pecuária ocasionam as maiores mudanças, seguidas do desmatamento e urbanização." Isso revela a centralidade do agronegócio na organização espacial, social, política e ambiental. Sobre essa percepção, Pegorare et al. (2017) sinalizam: "O agronegócio na Argentina, Brasil, Paraguai e Bolívia foi responsável por 80\% do desmatamento em toda a América Latina, entre 2001 e 2013."

\begin{abstract}
A expansão do cultivo da soja na América Latina tem levantado preocupações sobre a sua própria sustentabilidade, ou seja, o seu impacto a longo prazo sobre os recursos naturais, em especial as áreas de floresta. $\mathrm{O}$ desmatamento tem avançado em algumas áreas da Argentina, Brasil e Paraguai, o que poderia estar influenciando negativamente, acarretando mudanças climáticas na região sul da América (PEGORARE et al, 2017, p. $67)$.
\end{abstract}

Diante de tais impactos, a controvérsia sobre esse impulso agrícola, é a alteração da paisagem, do ponto de vista ecológico e ambiental e a transposição da organização social no território.

Nesse sentido, emergem conflitos territoriais, pelo confronto entre grandes grupos agroindustriais e suas infraestruturas, as populações locais e as organizações não governamentais, forças sociais antagônicas devido às formas de uso da terra e da água para produzir no território.

Esse modelo de manipulação é um problema de cunho territorial para absolutizar o espaço em favor de grupos estratégicos. Para Saquet (2015, p. 111), "[...] o território envolve, ao mesmo tempo, as relações efetuadas pelo homem na natureza/ambiente, compreendendo os grupos, as comunidades e suas percepções/sentimentos." Dessa forma, imprime mudanças necessárias para os ritmos do capitalismo para concentrar a terra e renda: 
A expansão da soja e do gado sobre os territórios indígenas e campesinos, é a mesma lógica de apropriação dos meios de produção, separando de seus meios de subsistência e cultura as populações. Desta maneira existem novas populações carentes de bases materiais de sobrevivência, que estão obrigadas a depender do mercado, e buscam formas de obter ingresso nas cidades ou zonas rurais urbanizadas. No novo território ocupado pelo mercado, se exige que tenha nova mão de obra 'livre', submissa a qualquer tipo de trabalho, competindo com os outros, expulsos anteriormente (ORTEGA, 2013, p. 39-40, tradução nossa).

As melhores terras passaram a pertencer a proprietários individuais ou empresas instaladas no Chaco. "O modo violento da apropriação das terras indígenas provocou resistências no território, derivando em desaparecimentos, mortes e expulsão dos habitantes" (ORTEGA, 2013, p. 57).

Os brasileiros passam pelas mesmas condições, conforme explicam PortoGonçalves et al. (2015, p. 90): “[...] o Brasil vem se constituindo num caso emblemático do processo expropriatório em curso em todo o planeta, nesses últimos 40 anos". Na Chapada dos Parecis, divisor de águas dos Rios Paraguai e Amazonas, localizada no noroeste do estado brasileiro do Mato Grosso, recoberta por cerrados, o grupo étnico Parecis teve seu território totalmente alterado e ressignificado para produção agropecuária exportadora a partir da segunda metade do século $X X$, proporcionada pelo governo através de vários programas e incentivos fiscais. Tal ocupação espacial era vista como em um território "vazio" que deveria ser ocupado, sob a lógica do capital privado. Nesta linha de reflexão, Arruzzo (2016, p. 148) não hesita em declarar que esse território “[...] de um imenso espaço 'vazio' (sic), passou a fazer parte do comércio internacional de commodities agrícolas e se tornou um importante elo na cadeia carne/grãos." Sempre dependentes do uso intensivo da água.

Já em 1867, Marx (1988) situava o trabalho e sua relação com o capital como fenômeno histórico, volúvel e incompatível, conceituando-o como acumulação primitiva, porque constitui a pré-história do capital e do modo de produção que lhe corresponde. E, ainda nessa empreitada, o autor denunciou as desigualdades sociais provocadas pelo capitalismo, demonstrando que as sociedades humanas progridem através da luta de classes:

A relação capital/trabalho pressupõe a separação entre os trabalhadores e a propriedade das condições da realização do trabalho, tão logo a produção capitalista se apoie sobre seus próprios pés, não apenas conserva aquela separação, mas a produz em escala sempre crescente. Portanto, 0 processo que cria a relação capital/trabalho não pode ser outra coisa que o processo de separação do trabalhador da propriedade das condições de seu trabalho, um processo que transforma por um lado, os meios sociais de subsistência e de produção em capital, e por outro, os produtores diretos em trabalhadores assalariados. Assim chamada, acumulação primitiva e 
portanto nada mais que o processo histórico da separação entre produtor e meio de produção, esse processo aparece como primitivo (MARX, 1988, p. 252).

Para reforçar esse entendimento, Porto-Gonçalves (2012, p. 35) acrescenta que "[...] a condição da reprodução das relações de produção capitalistas é a permanente separação dos povos e etnias das condições materiais de existência natureza incluída, além do caráter comunitário do modo de vida e de produção." Desta forma, sempre existiram relações conflituosas no território, seja no Chaco, seja no Pantanal e em outros espaços da Bacia do Prata. Mas territorialidades de poder exercidas pelo capital geram outras territorialidades que se opõe àquelas, como movimentos sociais de reforma agrária, sindicais, ambientais entre outros.

É importante entender que a territorialidade é disciplinada "[...] pelas ações desenvolvidas na tentativa de se formar um território, e mantê-lo, ou seja, de exercer controle sobre uma área para controlar pessoas e/ou recursos" (ARUZZO, 2016, p. 143). Dessa forma, cria-se um espaço relacional envolvendo a natureza e a sociedade intercedida pelo trabalho, segundo Milton Santos (1994, p. 33) que enfatiza "[...] o embate ancestral entre a necessidade e a liberdade dá-se pela luta entre uma organização coercitiva e o exercício da espontaneidade. O resultado é a fragmentação." Ou seja, a tribo unindo os homens pela "cooperação na diferença".

Especulamos que o conceito 'território' como habitat dos indivíduos poderia fechar esta evolução através da plena submissão do indivíduo cultural, controlando não apenas suas terras, mas 'protegendo' e 'conservando' suas tradições também (SAHR; SAHR, 2008, p. 154).

Ou seja, as condições naturais do espaço geográfico proporcionam a formação de territorialidades de poder na Bacia do Prata, e o ecossistema Pantanal é um fotograma dessa relação. Declarado Patrimônio Nacional pela Constituição Brasileira de 1988, o Pantanal faz parte do chamado Sistema Paraguai-Paraná de Zonas Úmidas, um complexo que abrange, além do Brasil, Argentina, Bolívia, Paraguai e Uruguai. Situado no interior da Bacia do Alto Paraguai (BAP), ocupa uma área aproximada de $200 \mathrm{mil} \mathrm{km}^{2}$, dos quais $70 \%$ no Brasil, $20 \%$ na Bolívia e 10\% no Paraguai (SCHLESINGER, 2014, p. 7).

Como mais um exemplo de que em muitos espaços da bacia a legislação não protege o povo e seus recursos naturais, Schlesinger (2014) denuncia que as maiores ameaças ao Pantanal hoje estão nas áreas de planalto e são oriundas das monoculturas, pecuária, mineração, hidrelétricas e siderurgia - todo o aparato estrutural promovido pelo Estado para promover a expansão capitalista. 
O desmatamento de áreas de nascentes, o assoreamento dos rios, a contaminação e a alteração do pulso natural das águas e a forte redução da quantidade de peixes são as principais consequências. Deste conjunto de ameaças, destaca-se o crescimento da área plantada com soja em áreas não inundáveis da Bacia do Alto Paraguai. Atualmente (2014), cerca de $10 \%$ do total da área plantada com soja em todo o Brasil encontram-se nesta região. [...] na Bacia do Alto Paraguai, não há qualquer dispositivo legal capaz de conter a expansão da soja (SCHLESINGER, 2014, p. 5, grifo nosso).

Os diversos dispositivos da Lei de Proteção da Vegetação Nativa (LPVN), denominada popularmente de Novo Código Florestal Brasileiro (Lei oㅜ 12.651, de 25 de maio de 2012), como a redução das áreas de preservação permanente às margens dos rios, expõe ainda mais a região ao crescimento desordenado de atividades predatórias, especialmente a oleaginosa soja:

Por que tanta soja? A soja é a cultura agrícola que, globalmente, vem crescendo em ritmo mais acelerado nas últimas décadas, estimulada pelo forte aumento do consumo de carnes, principalmente nos chamados países emergentes. Estima-se que $90 \%$ da soja produzida no mundo tenha como destino a fabricação de farelo utilizado em rações animais, como fonte de proteínas (SCHLESINGER, 2014, p. 19, grifo nosso).

Dessa forma, os nexos entre produção de grãos e carne atraem empresários dessa área, forjando novos territórios nos países, pois as empresas desse ramo migram conforme a disponibilidade dos insumos.

\section{Os negócios territoriais e seus vínculos}

A evolução das técnicas, a fluidez da cadeia, fazem com que os processos produtivos redefinam e modelem seus territórios específicos, para produzir e movimentar o capital. À luz desse contexto, Gabrid (2016, p. 104) explica que "[...] as maiores empresas elegem pontos de interesse em um país, sendo necessários que os lugares se adaptem às condições técnicas e políticas para sua instalação, mediante a adoção de normas e aportes financeiros, fiscais, trabalhistas etc."

A exemplo desse aspecto, a Brasil Foods (BRF S.A.), uma das maiores companhias de alimentos do mundo, é resultado da fusão da Sadia e Perdigão, duas tradicionais empresas catarinenses. Apesar de terem "nascido" no oeste do estado brasileiro de Santa Catarina, a partir do qual se expandiram territorialmente possuindo unidades produtivas em toda a América Latina, Ásia, Europa e Oriente Médio, além de atuar em mais de 150 países, a nova empresa resultante da fusão 
continua executando transformações em escala local, porém, controla uma escala de negócios globais.

Nosso modelo de negócios é 'glocal', neologismo que nomeia o movimento simultâneo de globalização e valorização das características de cada região onde a BRF atua, e trabalhamos alguns pilares que ampliam nossas operações internacionais: investimento em marca; ampliação do portfólio; avanços na distribuição e aposta nas produções locais (BRASIL FOODS, 2017, [s.p.]).

Nesse modelo, a agropecuária se insere na globalização em grande escala envolvendo uma eficiente cadeia que se estende da produção ao consumo. Reconhecem Buhler; Guibert; Requier-Desjardins (2016, p. 27) que "[...] nos países com alto potencial produtivo como Argentina, o Brasil e o Uruguai, as agriculturas empresariais são sensíveis a essas evoluções, pois são progressivamente envolvidas em modos de funcionamento mais submetidos ás influências externas."

Em escala local esse tipo de negócio modela novos territórios, chamados por Gabrid (2016, p. 105) de "cidades do agronegócio", que são apoiados pelas iniciativas governamentais "[...] o estado pode engendrar estratégias de atração seletivas de empresas e investimentos privados, com políticas fiscais e ofertas de créditos a juros baixos, além de garantias de condições de infraestrutura, como a construção, ampliação de estradas, ofertas de energias e a construção de portos" (BRITTO, 2016, p. 56). Isso a transforma numa economia cada vez mais financeirizada. Não por acaso, as denúncias das "negociatas politiqueiras e corruptas" entre os representantes políticos e empresários são uma constante nesses países.

Esses grupos empresariais dispõem de tecnologia de ponta, que convergem em eficientes índices produtivos, o que foi fundamental para que a Bacia do Prata se firmasse como importante território polo do agronegócio do mundo, ou seja, o celeiro da exportação, tendo o soja como produto condutor dessa força motora, conforme mostra a figura 02 . 
Figura 02- PIB agropecuário brasileiro e principais culturas

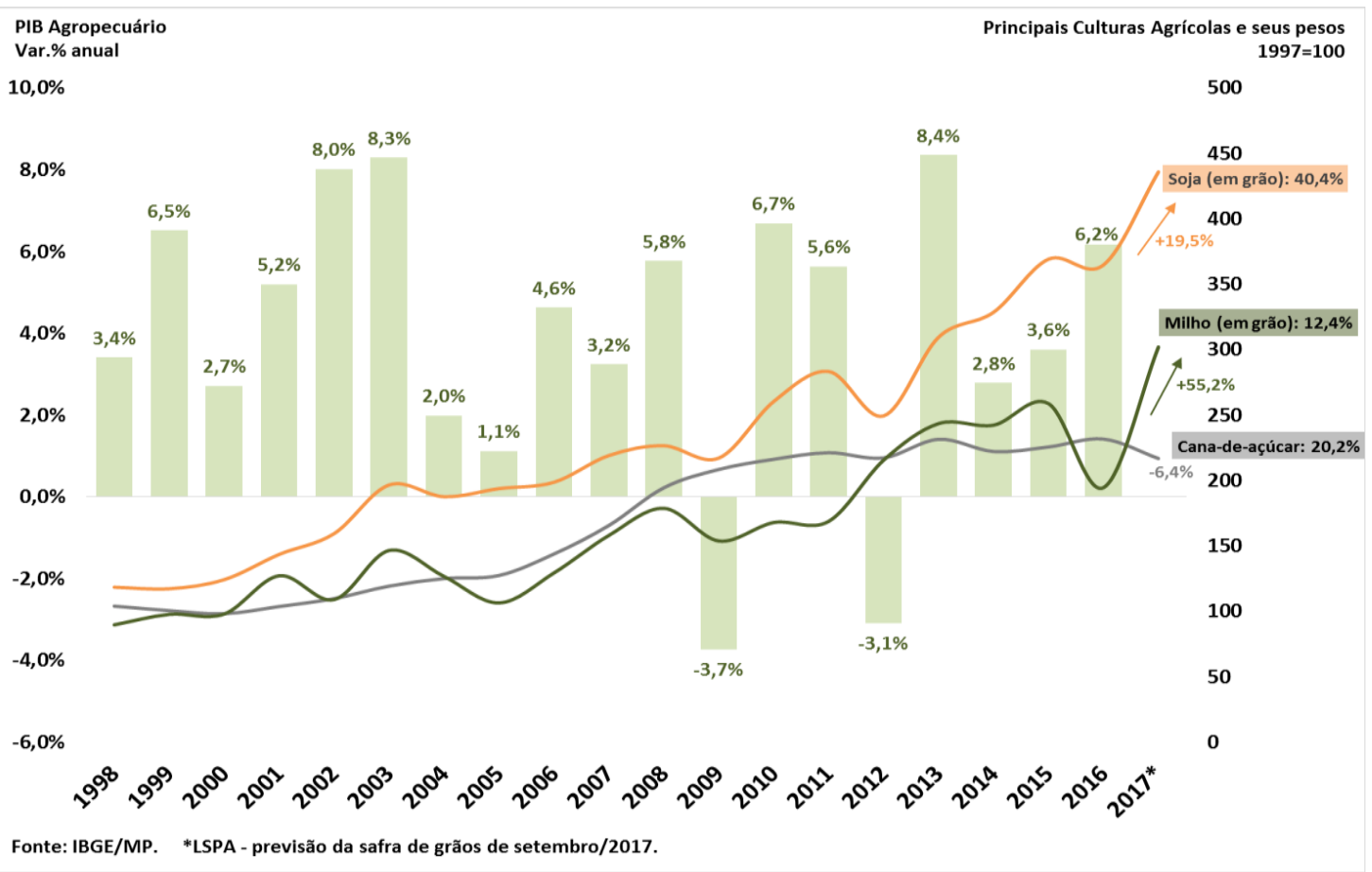

Fonte: Brasil (2017).

Neste processo, muitos produtores familiares são desalojados e relevantes áreas passaram a produzir produtos agropecuários industrializados ou semiindustrializados, voltados para a exportação em grande escala, gerando uma situação de privilégio econômico e uma nova classe de empresários agrícolas e agroindustriais, com grande concentração de terras e de renda.

A expansão da cultura da soja foi um dos principais responsáveis pela introdução do conceito de agronegócio no país, não só pelo volume físico e financeiro envolvido, mas também pela necessidade da visão empresarial de administração da atividade em si, por parte dos produtores, fornecedores de insumos, processadores da matéria-prima e negociantes, de forma a manter e ampliar as vantagens competitivas da produção (GATTI; SOBRINHO, 2006, [s.p.], grifo nosso).

Nesse formato, o agronegócio/hidronegócio é notável nos meios de negócios, que desfrutam dessa nova geografia do poder, que lidera a gestão do território através das atividades econômicas e produtivas; além dos efeitos nas relações sociais avultam os impactos ambientais, especialmente no tocante ao uso das águas.

É na região das nascentes do rio Paraguai que estão situadas as três maiores propriedades produtoras de soja e milho do município (Alto Paraguai). As fazendas Sete Lagoas e Paraguaizinho, operadas pelo grupo argentino El Tejar, ocupam, juntas, 3,9 mil hectares naquela área. A fazenda Sete Lagoas deve seu nome à existência, originalmente, de sete lagoas formadas pelas águas das nascentes do rio Paraguai. Hoje, restam apenas quatro delas. As outras três, cercadas até às margens por 
pastagens e lavouras de soja e milho, secaram em consequência do desmatamento (SCHLESINGER, 2014, p. 28).

Os monocultivos, principalmente da soja, aliados à pecuária extensiva, sobrepõem-se à aplicação de técnicas agrícolas sustentáveis, sem a devida aplicação das leis ambientais e a necessária fiscalização pelo governo.

\section{A lógica das grandes escalas de cultivos reflete-se nas escalas locais}

As grandes áreas de produção de soja geram efeitos nos cultivos locais, necessários à demanda interna para alimentação básica da população através das pequenas propriedades, que sofrem impactos causados pelos grandes cultivos da agricultura comercial agroexportadora, o que expulsa do campo boa parte desses pequenos agricultores, que migram para as cidades aumentando o número de desempregados urbanos.

Para o caso do Chaco, Torraca (2006) conclui:

Desse modo entende-se que o Chaco nunca pode desenvolver seu potencial devido à ausência de políticas públicas que possibilitassem a exploração da região pelos campesinos, porque, na maioria das vezes, o Estado fortaleceu a formação de latifúndios em detrimento da população local (TORRACA, 2006, p. 34).

Com a globalização e simultânea expansão do capital, "[...] antigas formas e padrões organizacionais dão lugar a novas lógicas, emergem novos usos do território, novas territorialidades, camponeses são deslocados para dar lugar à produção agrícola em larga escala, ou seja, ao agronegócio" (PEREIRA, 2015, p. 50 ); esse fator é gerador de diferentes escalas de olhares para o território, interpreta Santos (1996):

A ordem global funda as escalas superiores ou externas à escala do cotidiano. Seus parâmetros são a razão técnica e operacional, o cálculo de função e a linguagem matemática. A ordem local funda a escala do cotidiano, e seus parâmetros são a copresença, a vizinhança, a intimidade, a emoção, a cooperação e a socialização com base na contiguidade, (SANTOS, 1996, p. 272).

Essa coexistência de escalas indica uma convivência, embora cada vez menor, dos dois modelos de produção, fazendo com que os mesmos comportem na realidade, dois tipos de territórios: o do agronegócio e os dos camponeses e indígenas, cada vez mais descontínuos, com suas características particulares. Como pode ser observado na figura 03 , representando os diferentes usos da paisagem. 
Figura 03 - Tipos de paisagem resultantes dos usos diferenciados no Pantanal
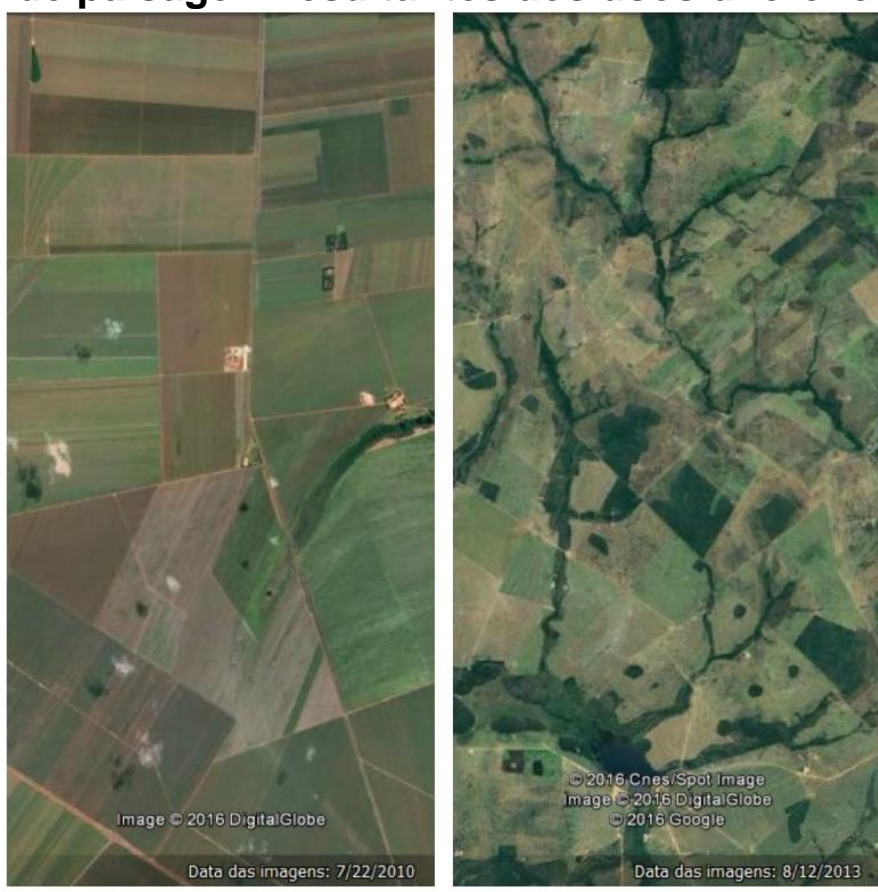

Fonte: Elaborada pelos autores (2018), a partir de imagens do Google Earth. Imagem da esquerda: Município de Diamantino-MT (14011'13.96"S e 56³2'47.28"O). Disponível em: <https://www.google.com.br/maps/@-14.3992385,-56.4540793,11888m/data=!3m1!1e3.url>. Acesso em: 8 fev. 2017. Imagem da direita: Município de Porto Espiridião-MT (1558'47.30"S e 5853’56.07"O). Disponível em: <https://www.google.com.br/maps/@-15.5807303,58.3926691,189160m/data=!3m1!1e3>. Acesso em: 8 fev. 2018.

As figuras ilustram um conjunto de elementos paisagísticos de espaços historicizados e produzidos pelas relações sociais, porém, existe distinção entre as diferentes realidades que mantêm sua individualidade. Para Souza (2013, p. 35), "[...] como projeção espacial de relação de poder, o território é no fundo em si mesmo, uma relação social, mas especificamente, uma relação social diretamente especializada." Na figura 03, observa-se essa relação de materialidade do espaço e sua relação social, ou seja, o espaço social está intrínseco no espaço geográfico.

Há diferença entre o modelo do agronegócio e a agricultura campesina e indígena. Os territórios do campesinato e os territórios do agronegócio são organizados de diferentes formas, a partir de diferentes relações sociais. $O$ território do agronegócio é para a produção de mercadorias (basicamente, rações!), enquanto as comunidades campesinas e indígenas organizam seus territórios para a subsistência, precisando desenvolver as dimensões da vida. Esta diferença se expressa na paisagem, onde podem ser observadas as distintas formas de organização dos territórios. A paisagem do território do agronegócio é homogênea, enquanto o território campesino é heterogéneo (ORTEGA, 2013, p. 50, tradução, grifos e parêntese, autores)

A forma de agir é diversa no território, comunidades campesinas e indígenas produzem alimentos na modalidade de subsistência e combate à fome, em escala 
local; contudo, o produtor individual fica refém da ação das grandes corporações capitalistas. Nessa linha de reflexão, Ortega; Portillo (2015) denunciam a complexidade do sistema de interesses que operam nas nuances do agronegócio, realidade no Paraguai, mas que se faz presente nos demais países platinos:

En el Paraguay, el principal producto de exportación es la soja, cuya área de cultivo ocupa $62 \%$ de un total de $5.637 .300 \mathrm{~h}^{2}$ destinadas a la producción agrícola; apenas $6 \%$ son destinadas a rubros agrícolas para alimentación (mandioca, poroto, batata y otros). El resto de la superficie, el $32 \%$, está cultivada con maíz, arroz con riego, trigo, caña dulce y canola, sumando alrededor del 93,8\% que es ocupada por la agricultura mecanizada. La superficie destinada al cultivo de soja fue de 3.500 .000 hectáreas en la campaña agrícola $2013 / 14$. El $70 \%$ de la soja producida en Paraguay se exporta en forma de grano (ORTEGA; PORTILLO, 2015, p. 50).

Outro fato que no Brasil gera perplexidade e apreensão quanto ao futuro dessa categoria social, segundo Tonin, Machado e Wives (2016, p. 91), foi "[...] a recente extinção do Ministério do Desenvolvimento Agrário, criado em 2002, e que possuía como público alvo os agricultores familiares."

O agronegócio pode ser tratado como algo mais amplo que o latifúndio, uma vez que concentra terra, tecnologia e políticas de desenvolvimento. $O$ agronegócio transmite a imagem de único produtor de alimentos, garantindo a segurança alimentar do Brasil, quando na realidade o agronegócio produz commodities para a exportação (PEREIRA, 2015, p. 72).

Porto; Rocha; Pacheco (2015, p. 134) enfatizam que "[...] os monocultivos implicam em redução da biodiversidade e em técnicas artificiais de lidar com o crescimento dos plantios. $O$ desequilíbrio assim produzido é enfrentado por uma verdadeira guerra química, cuja arma principal são os agrotóxicos." A presença desses produtos, e especialmente dos fertilizantes químicos nas lavouras, além dos impactos nas águas e na saúde, inviabilizam a permanência dos pequenos produtores familiares no campo, aliando-se a isso a falta de assistência técnica, de créditos e incentivos governamentais. Isto é, o uso do produto químico acaba afetando toda cadeia, tanto no que diz respeito à vida natural quanto no que diz respeito à vida humana na sociedade.

\section{O agronegócio e sua infraestrutura: hidrovia Paraguai-Paraná}

Os novos fronts do agronegócio conduzem a diferentes necessidades de ampliar seus territórios e territorialidades em suas diversas temporalidades. No 
processo de produção, a navegação, desde os tempos coloniais liga os diferentes territórios platinos de forma global.

O interesse pelo potencial econômico do transporte hidroviário existente nesses rios há muitos séculos e o empenho dos governos na viabilização das condições técnicas e econômicas para as obras de balizamento, retirada de rochas e dragagem dos Rios Paraguai e Uruguai estão diretamente ligados aos processos de formação do Mercosul (TREVISOL, 2007, p. 120).

O fato é que o escoamento da produção se dá pela Bacia do Prata, reforçando a dupla importância econômica das águas, tanto como fonte de vida dos produtos, quanto de distribuição geográfica através da navegabilidade, assim necessitando de grandes investimentos de infraestrutura.

A conjuntura forjada por motivos geoestratégicos marca o território que se tornou versátil. Em suas diferentes fases geoeconômicas, a questão dos investimentos em grandes obras hidrográficas demonstra a autoridade das corporações sobre a formação de territorialidades com apoio das políticas públicas, a serviço do agronegócio:

Dentro de um mesmo Estado Territorial, que se crê nacional, existem múltiplas territorialidades - campesinidades várias, várias etnias, vários povos, várias nacionalidades; que a natureza não é recurso natural nem capital natural, mas fonte de vida e ela mesma riqueza; enfim, que o território não é simplesmente um substrato, mas tem espessura, densidade: natureza + cultura através das relações de poder (PORTO-GONÇALVES et al., 2015, p. 97).

Território e escala são significativas ferramentas para explicar essa complexidade de territorialidades conflitantes, conduzindo a refletir sobre os benefícios econômicos gerados pela disponibilidade hídrica, sendo usufruídos por um pequeno grupo de corporações nacionais e internacionais, denuncia Fernandes (2015) que

[...] o estado é que define o uso prioritário da água. É verdade! Mesmo assim, quem dá o comando é o capital, através do Estado, independente do que reze a lei, e, nesse sentido, tanto as regiões quanto seus povos, que dependem diretamente da água para viver, e não para fazer negócio, ficam fragilizados, (FERNANDES, 2015, p. 115).

Ou seja, a água está a serviço do capital com o apoio dos governos. 


\section{Impactos dos diferentes usos das águas platinas}

A lógica mercantilista na bacia platina utiliza seus recursos naturais, em suas múltiplas funções, gerando perturbações negativas no solo, flora, fauna e nas águas superficiais, que são conectadas com as águas subterrâneas.

No alto Paraguai os conflitos ambientais são ligados à mineração, erosão dos solos, navegação. No alto e médio e baixo Paraná, ao desmatamento, erosões, contaminação por pesticidas ligados ao agronegócio, além das inundações urbanas e ribeirinhas, efluentes das cidades, navegação e energia. No alto Uruguai, conflitos de uso da água entre Brasil e Uruguai, além dos transtornos ligados às hidrelétricas e pela navegabilidade. Nas porções média e baixa desse rio, há mudanças no leito causando erosão, inundações ribeirinhas. O estuário do Rio da Prata, recebe os diferentes impactos de montante, da navegação, assoreamentos e os impactos advindos das grandes áreas urbanas de Buenos Aires e Montevidéu.

Esses e outros problemas são apontados no documento publicado pelo CIC com o título: Análisis Diagnóstico Transfronterizo de la Cuenca del Plata (2016).

As atividades agrícolas são as maiores consumidoras de água e modificadoras do solo da Bacia do Prata, "[...] los principales cultivos corresponden a ciclos anuales: soja, trigo, maíz y arroz. El arroz es producido con riego por inundación y es uno de los grandes consumidores de agua" (ANÁLISIS DIAGNÓSTICO TRANSFRONTERIZO DE LA CUENCA DEL PLATA, 2016, p. 20).

Apesar da cultura da soja ser de grande extensão, essa produção não exige uma quantidade expressiva de água além daquela das chuvas, contudo, o uso dos fertilizantes químicos sintéticos e agrotóxicos, contaminaram as águas, além do transporte hidroviário para exportação, já que a Argentina e o Brasil juntos são os maiores exportadores desta commodity no planeta.

Já o arroz, necessita de muita água para seu cultivo, além dos impactos causados pelo intenso uso de insumos e agrotóxicos, sendo as maiores plantações de arroz centralizadas no estado Rio Grande do Sul e no norte do Uruguai.

Outra questão é que, embora os arrozais sejam habitat de diferentes espécies e receberem aves migratórias, o cultivo de arroz ocasiona perdas na biodiversidade, que está sendo ameaçada de extinção. Existem estudos demonstrando que cresce o número de ameaças à fauna:

Sin embargo, el uso creciente de agroquímicos, el manejo inadecuado de los recursos hídricos, la introducción accidental o deliberada de especies exóticas invasivas y la conversión inapropiada hacia otros tipos de uso de suelo, asociados a los cultivos de arroz impactan en forma negativa a los 
recursos naturales, el suelo, agua y biodiversidad (FRIEDMAN, WEIL, 2010, p. 49).

No Brasil, as atividades industriais estão mais centralizadas no sul/sudeste.

Além da produção agrícola e industrial, os rios da Bacia do Prata geram o maior potencial de energia hidrelétrica da Argentina, Brasil, Paraguai e Uruguai agravando os conflitos e seguridade hídrica causada pelas diferentes funções da água:

El principal impacto sobre el desarrollo urbano se observa sobre la reducción de la seguridad hídrica, en particular en aquellas ciudades que están en las cabeceras de los ríos y con población muy grande; además, la disminución de los caudales agrava la capacidad de dilución de efluentes sin tratamiento (ANÁLISIS DIAGNÓSTICO TRANSFRONTERIZO DE LA CUENCA DEL PLATA, 2016, p. 26).

$\mathrm{Na}$ bacia hidrográfica onde se manifesta a maioria das consequências ou impactos do uso dos recursos naturais, eles se manifestam como: erosão dos solos, lixiviação de nutrientes, assoriamento de rios, lagos e reservatórios, degradação de matas ciliares e da cobertura vegetal, deposição de resíduos sólidos, dejetos e efluentes decorrentes de atividades humanas, cheias e inundações, endemias e epidemias de veiculação hídrica (BRASIL - A IRRIGAÇÃO NO BRASIL SITUAÇÃO E DIRETRIZES, 2008, p. 26).

\begin{abstract}
Sem ser uma exceção, os rios da Bacia do Prata estão sujeitos a pressões modificadoras da quantidade e qualidade de suas águas. Essas pressões são, fundamentalmente, de variações extraordinárias no regime hidrológico, parcialmente vinculadas a variações e mudanças climáticas, bem como aos fatores associados com a mudança no uso da terra, o crescimento populacional, agricultura, indústria e infraestrutura para o desenvolvimento em geral (SOLA, 2015, p. 95).
\end{abstract}

Para discutir os problemas ambientais e, buscar soluções, várias reuniões internacionais e estudos técnicos têm sido realizados pelos países platinos.

\title{
Considerações Finais
}

Os territórios estão em movimentos contínuos, um ciclo constante, Haesbaert (2009, p. 138) afirma que "a dinâmica mais comum é que passemos de um território para o outro". O fenômeno do agronegócio movimentou, revolucionou e remodelou a vida em todas as suas formas no espaço platino, traçando uma nova geografia de poder: "a desterritorialização, associada ao mito da revolução, e domínio do universo científico-tecnológico inerente à reprodução capitalista, seria a marca da sociedade moderna" (Haesbaert, 2009, p. 149). 
O progresso tecnológico associado às formas de produzir a terra e a função da água, o cultivo de soja e de cereais, estão totalmente relacionados com a hidrografia do espaço: a realidade é que $70 \%$ da água consumida no mundo é usada para produzir alimentos, e mesmo assim o planeta está com número expressivo de seres humanos passando fome, "a questão fundamental para que ocorra o bem estar social é o gerenciamento da riqueza produzida pelo crescimento do agronegócio, aplicado em políticas públicas, no sentido da diminuição das desigualdades sociais"(PEGORARE et al, 2017, p. 69).

A função do Estado no tema cultivo de alimentos deveria transcender sua função estatal reguladora, com uma visão sistêmica dos ideais de autonomia e cidadania, "[...] o estado territorial teve, desde o seu nascimento, um papel ambíguo: controlar e classificar através do espaço, mas não simplesmente para reter entre suas fronteiras [...], sempre foi um gestor fundamental do capitalismo" (Haesbaert, 2009, p. 151).

Mesmo que as fronteiras continuem abertas para circulação ou para o fluxo das mercadorias, advindos de processos produtivos que especializam determinada espécies comerciais, tornam-se grandes regiões produtivas onde um único produto símbolo da região, nesse caso a soja, desempenha essa função.

As grandes áreas para plantios de soja causam sequelas aos ecossistemas, gerando diferentes passivos, tais como: diminuição da circulação de água no solo, alteração no ciclo de nutrientes, desmatamentos, contaminação de rios e aquíferos por agrotóxicos, modificação na paisagem e na vida das comunidades indígenas e campesinas em muitos momentos violando direitos humanos, momento em que o uso da água promove conflitos com a população numa escala local, que sofrem os impactos causados nos territórios, conforme Achkar, (2015, p. 52-53) "El capital se apodera de la naturaliza [...], expulsa a comunidades campesinas e indígenas, contamina los ríos, el ambiente, provoca la mortandad de animales, destrucción de especies vegetales, se apropia de los conocimientos ancestrales."

Neste sentido, o ofício da água é transformado a partir da tecnologia, convertendo a água para o seu fluxo contínuo, para a energia, para armazenagem, para a navegação, esse mesmo aparato tecnológico converte o agricultura em agronegócio, que já não é agricultura para produzir alimentos, mas sim rações - e riqueza para poucos.

A função do Estado-Nação tornou-se aliada ao propósito do capital financeiro agroexportador, articulando as políticas públicas para legitimar o poder no território, 
eliminando impedimentos por meio da legislação, organizando o processo de movimento da produção, mediante a manutenção da malha viária: ferrovias, hidrovias, portos, aeroportos, acesso à energia entre outros.

O fato é que o conjunto dos territórios que conformam a Bacia do Prata como um grande "Território das Águas" (ZENI, 2018), foi produzido a partir do aproveitamento de recursos hídricos, não importa o momento histórico. Na realidade hodierna, a água se constitui no insumo de maior valor para o agronegócio; sem esse recurso o agronegócio deixa de existir, pois para produzir commodities para exportar para os mercados globais necessita água.

O estado não tem uma gestão de fato dos recursos naturais, já que alguns grupos dessa agricultura empresarial têm o controle sobre a águas superficiais dos grandes rios platinos e seus tributários e as águas subterrâneas, em especial dos aquíferos Serra Geral e Guarani, além de toda a cadeia da produção em larga escala. Sobre as modificações nos territórios hídricos introduzidas pela tecnologia, Pinheiro $(2018, s / p)$, defende "nossa economia depende hoje de um agronegócio que não é agricultura [..], hoje, uma safra ruim significa PIB negativo, pois não temos mais industrialização".

Sobre o aumento do PIB brasileiro, segundo o IBGE (2017), no Brasil a exportação de soja atingiu patamares recordes em comparação ao ano anterior; além disto, a produtividade ajudou a impulsionar a participação da agricultura no PIB do país e a diminuir o impacto das quedas de outros setores, "com a estimativa de produção de 240 milhões de toneladas e crescimento de mais de 30\% em relação à safra do ano anterior, o ano de 2017 termina com resultados recordes na agricultura" (IBGE, 2017, p. 22).

Ainda, conforme a Revista Retratos publicada pelo IBGE (2017), os dados do Centro de Estudos Avançados em Economia Aplicada (CEPEA) enunciam que "praticamente todos os segmentos do agronegócio tiveram desempenho positivo, gerando crescimento de 5,81\% no PIB-volume do agronegócio" (IBGE, 2017, p. 22).

Esses números identificam aspectos essenciais do processo de expansão dos agronegócios e sua consolidação territorial na Bacia do Prata: Brasil, Argentina, Bolívia e Paraguai, estão entre os maiores produtores de grãos do mundo - e o Uruguai para o caso do arroz.

Assim, as contradições dos tempos modernos: dinâmica do mercado, atuação do estado, uso da tecnologia, conflitos entre os diferentes grupos sociais, são 
características associadas com a forma de uso do território e os recursos naturais de forma mecanicista.

A problemática social e ambiental da contemporaneidade tecnológica, não somente na Bacia do Prata, mas em escala planetária, é um passivo histórico, produzido pelos desdobramentos das relações tecidas pela rede de poder emergindo em diversas escalas, diferentes territorialidades.

Diante de tantas questões, é inegável que o planeta está necessitando de novos significados territoriais com outros paradigmas planetários; quiçá o que Milton Santos conceituou de "outra globalização" seria uma sociedade renovada, eliminando as diferenças. Nessa "outra irmandade global", a política teria a habilidade de um olhar sustentável que contemplaria um bem maior, chamado coletividade, baseado na lógica da solidariedade, inclusão, ou seja, um "ser" o território e não um "ter" o território. E a água? Assumiria o seu papel maior, como sustentáculo da vida...

\section{REFERÊNCIAS}

ACHKAR, Marcel. Agua y territorio: un sistema interactivo. REDES - Amigos de la Tierra Uruguay, Montevideo, p. 401-449, 2015. Disponível em:

https://www.redes.org.uy/2015/03/12/ . Acesso em: 20 jan. 2018.

ARRUZZO, Roberta Carvalho. De "espaço vazio" ao mercado mundial de commodities agrícolas: estratégias e relações territoriais na Chamada dos Parecis nos anos 1960 e 1970. In: BERNARDES, Júlia Adão; BUHLER, Éve Anne; COSTA, Marcos Vinícius Velozo da (Org.). As novas fronteiras do Agronegócio: transformações territoriais em Mato Grosso. Rio de Janeiro: Lamparina, 2016. 168 p.

BRASIL. Ministério da Integração Nacional. Secretaria de Infra-Estrutura Hídrica. Departamento de Desenvolvimento Hidroagrícola. Irrigação no Brasil: situação e diretrizes. Brasília: Instituto Interamericano de Cooperação para a Agricultura, 2014. Disponível em: http://www.integracao.gov.br/documents/10157/3672008/A+irrigacao+no+Brasil++diretrizes.pdf/b88c745b-f5b3-4f3d-b375-483033a2e80c . Acesso em: 17 jul. 2018.

SEPLAN - Secretaria de Planejamento e Assuntos Econômicos. Panorama Macroeconômico. Brasília: SEPLAN, nov. 2017. Disponível em: http://www.planejamento.gov.br/ . Acesso em: 4 dez. 2017.

BRASIL FOODS - BRF S/A. Sobre a BRF. 2017. Disponível em: https://www.brfglobal.com/sobre-brf/onde-estamos\#o-que-fazemos . Acesso em: 28 nov. 2017.

BRITTO, Fabio Giusti Azevedo de; SILVA, Simone dos Santos Sodré da; ANACHE, Bernardo Mansur. Técnica, território e impactos ambientais no "celeiro" das commodities agrícolas. In: BERNARDES, Júlia Adão; BUHLER, Éve Anne; COSTA, Marcos Vinícius

${ }^{6}$ In "Encontro com Milton Santos: O mundo global visto do lado de cá", dir. Silvio Tendler, 2006. 
Velozo da (Org.). As novas fronteiras do Agronegócio: transformações territoriais em Mato Grosso. Rio de Janeiro: Lamparina, 2016. 168 p.

BUHLER, Éve Anne; GUIBERT, Martine; REQUIER-DESJARDINS, Marcos Vínicius. As agriculturas empresariais na Argentina, no Brasil e no Uruguai: Uma globalização dos espaços rurais? In: BERNARDES, Júlia Adão; BUHLER, Éve Anne; COSTA, Marcos Vinícius Velozo da (Org.). As novas fronteiras do Agronegócio: transformações territoriais em Mato Grosso. Rio de Janeiro: Lamparina, 2016. 168 p.

COMITÊ INTERGOVERNAMENTAL COORDENADOR DOS PAÍSES DA BACIA DO PRATA - CIC. Buenos Aires, 2016. Disponível em: https://cicplata.org/es/una-potencia-mundial/ Acesso em: 24 dez. 2018.

Análisis diagnóstico transfronterizo de la cuenca del plata - ADT. Buenos Aires: CIC, 2016. Disponível em: https://cicplata.org/es/documentos-principales/ . Acesso em: 10. Jan. 2019.

CIH - Comitê Intergovernamental da Hidrovia Paraguai-Paraná. Hidrovia Paraguai-Paraná. 2017. Disponível em https://cicplata.org/es/documentos-principales/ . Acesso em: 28 nov. 2017.

ESPÍNDOLA, Marcos Aurélio. As transterritorializações na Bacia do Rio Uruguai e o alagamento sistemático de coletividades. 2009. 286 f. Tese (Doutorado em Geografia) Programa de Pós-graduação em Geografia, Centro de Filosofia e Ciências Humanas, Universidade Federal de Santa Catarina, Florianópolis, 2009.

FERNANDES, Antônio Claret. A dança dos números nos conflitos pela água. In: CANUTO, Antônio Canuto; LUZ, Cássia Regina da Silva; ANDRADE, Thiago Valentim Pinto Andrade (Coord.). Conflitos no Campo: Brasil 2015. Goiânia: CPT Nacional - Brasil, 2015. 240 p. Disponível em: https://www.cptnacional.org.br/index.php/component/ idownloads/send/41conflitos-no-campo-brasil-publicacao/14019-conflitos-no-campo-brasil-2015 . Acesso em: 3 nov. 2017.

FRIEDMAN, Alexandra. WEIL, Betsabe. Arroz Negocio Creciente. Agencia del Gobierno de los Estados Unidos para el Desarrollo Internacional (USAID). 2010. Disponível em: https://www.usaid.gov/sites/default/files/documents/1862/arroz.pdf. Acesso em 20 jan. 2019.

GABRID, Israella Pires Alves. O processo de produção e os agentes modeladores das cidades do agronegócio. In: BERNARDES, Julia Adão; BUHLER, Éve Anne; COSTA, Marcos Vinícius Velozo da (Org.). As novas fronteiras do Agronegócio: transformações territoriais em Mato Grosso. Rio de Janeiro: Lamparina, 2016. 168 p.

GATTI, Flavio; SOBRINHO, Rosangela Alves R. Novas territorialidades advindas da expansão da soja no Médio Norte Mato-Grossense - o município de Diamantino/MT. Cuiabá: UFMT, 2006. Disponível em: http://www.augm-cadr.org.ar/archivos/7mocoloquio/mesa 3/20080214.pdf . Acesso em: 24 nov. 2018.

HAESBAERT, Rogério. O mito da destorritorialização: do fim dos territórios à multiterritorialidade. 4. ed. Rio de Janeiro: Beltrand Brasil, 2009a. 396 p.

INSTITUTO BRASILEIRO DE GEOGRAFIA E ESTATÍSTICA_IBGE . Milho e soja: safra recorde. Revista Retratos, 2017. Disponível em:

https://agenciadenoticias.ibge.gov.br/media/com mediaibge/arquivos/3ee63778c4cfdcbbe4684937273d15e2.pdf . Acesso em: 20 jan. 2018.

MARX, Karl. O capital: contribuição à crítica da economia política. Tradução Regis Barbosa e Flávio Kothe. 3. ed. São Paulo: Nova Cultural, 1988. 
MENEZES, Daniel Junges; TRENTIN, Romario. Mapeamento do uso do solo na bacia hidrográfica do rio Quaraí sob a perspectiva da orizicultura e a demanda de água associada nas porções brasileira e uruguaia. Ciência e Natura, Santa Maria, v. 36, n. 3, p. 385-392, set./dez. 2014. Disponível em: http://periodicos.ufsm.br/ cienciaenatura/article/view/12277 . Acesso em: 20 jun. 2017.

ORTEGA, Guillermo. Extractivismo en el Chaco paraguayo: un estudio exploratório. Asunción: Investigaciones Sociales BASE, 2013. Disponível em:

http://209.177.156.169/libreria cm/archivos/pdf 1239.pdf .Acesso em: 25 out. 2017.

; PORTILLO, Ana. El agua: ¿bien común o mercancía?. Asunción: Investigaciones Sociales BASE, mar. 2015.

PEGORARE, Alexander Bruno et al. Panorama do agronegócio na América Latina: uma análise exploratória (2000-2015). Revista Brasileira de Agropecuária Sustentável, v. 7, n. 1, p. 59-72, mar. 2017. Disponível em:

https://www.researchgate.net/publication/317021815 PANORAMA DO AGRONEGOCIO N A AMERICA LATINA UMA ANALISE EXPLORATORIA 2000-2015. Acesso em 22 jan. 2019

PEREIRA, Lorena Izá. O processo de estrangeirização da terra no Brasil: estudo de caso da empresa Umoe Bioenergy no município de Sandovalina (SP). 2015. Dissertação

(Mestrado Geografia) - Faculdade de Ciências e Tecnologia, Universidade Estadual Paulista "Júlio de Mesquita Filho", São Paulo, 2015. Disponível em: https://repositorio.unesp.br/handle/11449/124298 . Acesso em: 22 jan. 2018.

PORTO-GONÇALVES, Carlos Walter et al. Bye bye Brasil, aqui estamos: a reinvenção da questão agrária no Brasil. CANUTO, Antônio Canuto; LUZ, Cássia Regina da Silva; ANDRADE, Thiago Valentim Pinto Andrade (Coord.). Conflitos no Campo: Brasil 2015. Goiânia: CPT Nacional - Brasil, 2015. 240 p. Disponível em: https://www.cptnacional.org.br/index.php/component/ jdownloads/send/41-conflitos-nocampo-brasil-publicacao/14019-conflitos-no-campo-brasil-2015 . Acesso em: 8 dez. 2018.

A ecologia política na América Latina: reapropriação social da natureza e

reinvenção dos territórios. Revista Interdisciplinar INTERthesis, Florianópolis, v. 9, n. 1, p. 16-50, jan./jul. 2012. Disponível:

https://periodicos.ufsc.br/index.php/interthesis/article/view/1807-1384.2012v9n1p16 Acesso em: 20 nov. 2018.

PORTO, Marcelo Firpo; ROCHA, Diogo Ferreira da, PACHECO, Tania. Agrotóxicos, armas de uma guerra não declarada. In: CANUTO, Antônio Canuto; LUZ, Cássia Regina da Silva; ANDRADE, Thiago Valentim Pinto Andrade (Coord.). Conflitos no Campo: Brasil 2015. Goiânia: CPT Nacional - Brasil, 2015. 240 p. Disponível em: <https:// www.cptnacional.org.br/index.php/component/jdownloads/send/41-conflitos-no-campo-brasilpublicacao/14019-conflitos-no-campo-brasil-2015> . Acesso em: 8 dez. 2017.

SAHR, Cicilian Luiza Löwen; SAHR, Wolf Dietrich. Territórios: Faxinais - espaços: a problemática "espaço/território" na formação social brasileira. In: SAQUET, Marcos Aurelio; SPOSITO, Eliseu Savério (Org.). Territórios e territorialidades: teorias, processos e conflitos. São Paulo: Expressão Popular; UNESP, 2008. 368 p.

SANTOS, Milton. A natureza do espaço: técnicas e tempo, razão e emoção. São Paulo: Editora da USP, 1996.

Técnica, espaço, tempo, globalização e meio técnico-cientifico-informacional. São Paulo: Hucitec, 1994. 
; SILVEIRA, María Laura. O Brasil: território e sociedade no início do século XXI. Rio de Janeiro: Record, 2001.

SAQUET, Marcos Aurelio. Abordagens e concepções sobre o território. 4. ed. São Paulo: Outras Expressões, 2015, 192 p.

SCHLESINGER, Sergio. Pantanal por inteiro, não pela metade: soja, hidrovia e outras ameaças à integridade do Pantanal. 2014. Disponível em: http://fase.org.br/wp-

content/uploads/2014/12/rev PORT pantanal fase MT.pdf . Acesso em: 20 out. 2018.

SOLA, Fernanda. Direito Internacional Ambiental da Bacia do Prata. Curitiba:

GEDAI/UFPR, 2015. 275 p. Disponível em: http://www.gedai.com.br/wpcontent/uploads/2015/06/direito internacional ambienta prata.compressed-1.pdf . Acesso em. 21 dez. 2018.

SOUZA, Marcelo José Lopes. Os conceitos fundamentais da pesquisa sócio-espacial. Rio de Janeiro: Bertrand Brasil, 2013. 320 p.

TONIN, Jefeson; MACHADO, José Tobias Marks; WIVES, Daniela Garcez. Evolução e diferenciação dos sistemas agrários: a situação da agricultura familiar de Cerro Largo e Salvador das Missões. Revista de Gestão do Agronegócio da UNIPAMPA, v. 2, n. 1, jul./dez. 2016. Disponível em: http://seer.unipampa.edu.br/index.php/agropampa/ article/view/23060/8671. Acesso em: 4 dez. 2017.

TORRACA, Mirta Mabel Escovar. Imigração e Colonização Menonita no Processo de Legitimação do Chaco Paraguaio (1921-1935). 2006. Dissertação (Mestrado em História) - Universidade Federal da Grande Dourados, Dourados, 2006.

TREVISOL, Joviles Vitório. Atores sociais e meio ambiente: análise de uma rede transnacional de organizações da sociedade civil. Chapecó: Argos, 2007. 295 p.

ZENI, Vera Lucia Fortes. Bacia do Prata: o território das águas. Tese (doutorado em geografia).Universidade Federal de Santa Catarina, Florianópolis, 2018.

ZUGAIB, Eliana. A hidrovia Paraguai-Paraná. Brasília: Fundação Alexandre de Gusmão, 2007. 438 p. Disponível em: http://funag.gov.br/loja/download/0357-

hidrovia paraguai parana.pdf Acesso em: 12 nov. 2018

\section{NOTAS DE AUTOR}

\section{CONTRIBUIÇÃO DE AUTORIA}

Vera Lucia Fortes Zeni - Concepção. Coleta de dados, Análise de dados, Elaboração do manuscrito e versão final do trabalho

Luiz Fernando Scheibe - Participação ativa da discussão dos resultados; Revisão e aprovação da versão final do trabalho.

Elton Zeni - Participação na discussão dos resultados; Revisão e aprovação da versão final do trabalho. Marcilei Andrea Pezenatto Pezenatto Vignatti - Revisão e aprovação da versão final do trabalho.

\section{FINANCIAMENTO}

Conselho Nacional de Desenvolvimento Científico e Tecnológico - CNPq - e da Rede Guarani/Serra Geral RGSG

\section{CONSENTIMENTO DE USO DE IMAGEM}

Não se aplica

APROVAÇÃO DE COMITÊ DE ÉTICA EM PESQUISA

Não se aplica 
CONFLITO DE INTERESSES

Não se aplica

\section{LICENÇA DE USO}

Este artigo está licenciado sob a Licença Creative Commons CC-BY. Com essa licença você pode compartilhar, adaptar, criar para qualquer fim, desde que atribua a autoria da obra.

HISTÓRICO - uso exclusivo da revista

Recebido em: 01-02-2019

Aprovado em: 01-04-2019 